\title{
Legislative Naiveté of Librarians
}

Do librarians appreciate or understand the subtleties of the legislative processes? After participating in the recent Conference on Federal Information Resources, I am convinced the answer is-no, they do not. Librarians are still resentful of recent government actions which suggest a downgrading in priorities for support of libraries, but worse, we seem to be incapable of reversing the trend. One positive step is for academic librarians to be introduced to the Office of Management and Budgeting within the Executive Branch. The OMB is an enormously influential office. It is staffed by planners, economists, and other fiscal experts in whose hands largely rests the future of federal support to libraries. These specialists do not hold grudges against libraries. On the contrary, most of them know very little about libraries-their operations, objectives and aspirations, or potential social contributions. Their knowledge is probably limited to individual, unique experiences of childhood and student days. One speaker reported that in a recent meeting with an OMB official, the first question he was asked was "what is a library; what is it trying to do?" From this, it appears that we have nowhere to go but up.

On several occasions during the conference, librarians' resentments toward the present administration surfaced, but will our unhappiness alone alter present administration attitudes? As one federal librarian acidly noted, name-calling will not advance the cause of libraries in the eyes of the administration. In fact, he observed that the present library predicament was largely the fault of the library community. Librarians have failed to sell their programs, or in today's parlance, to demonstrate a persuasive cost effectiveness.

At one point, a member of COSATI nearly exploded. He admonished the conferees for their apparent political naiveté; he said he was particularly appalled since those attending possibly represented the cream of librarianship.

With a few notable exceptions, such as Gerry Krettek and Stephen McCarthy, who have both served the profession ably in Washington, many of us know too little about the circuitous, seemingly arcane legislative procedures. Of course, name-calling, complaining, or self-immolation will not win the day for librarianship. Considering the political climate for the foreseeable future, not only for libraries but for higher education in general, ACRL would do well to consider positive action to improve the legislative acumen of its members. A series of workshops staffed by librarians and others who are experienced in working with state and federal legislators would represent one immediate step. Greater efforts to sell the case for librarianship to our colleagues in other disciplines is another worthwhile approach. We certainly won't sell the case for librarianship talking to each other at ALA meetings.

R. M. DOUgherTy 


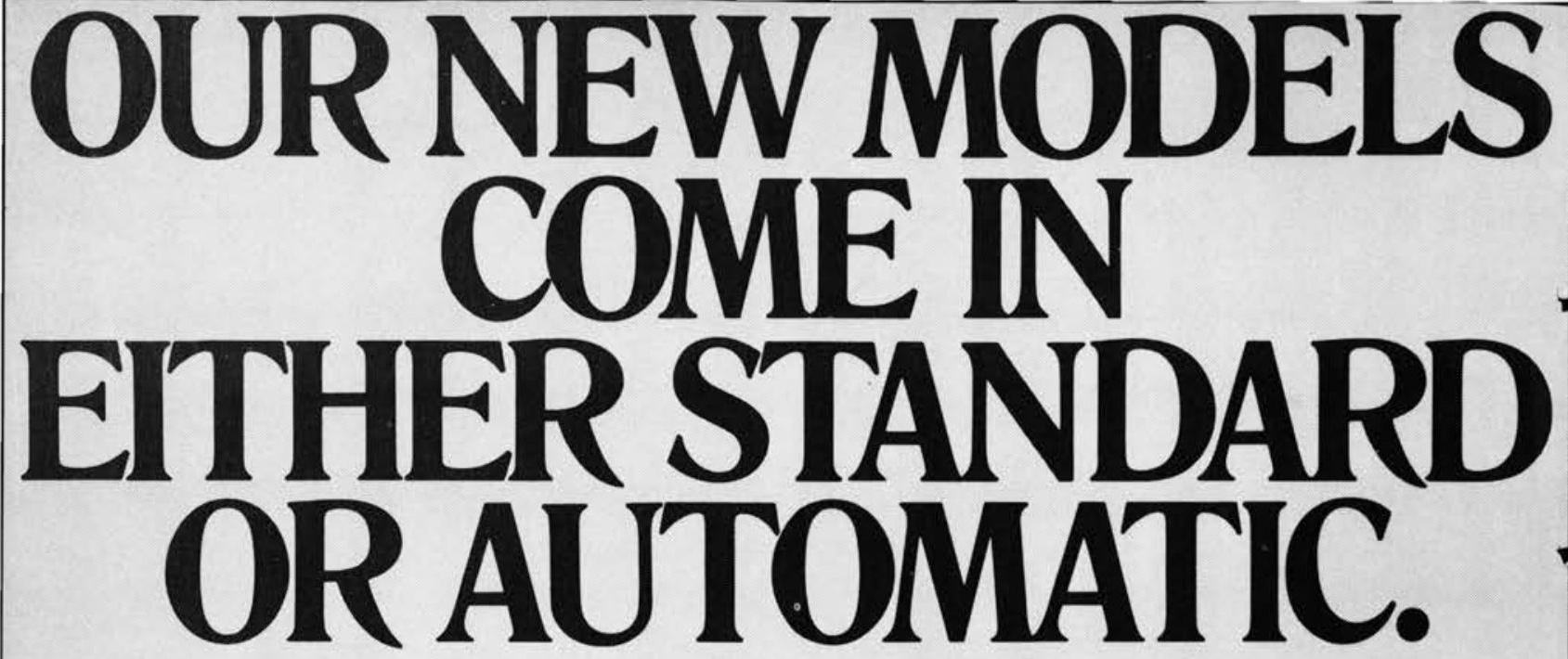

At $\$ 119$, our model 1212 (below, left) is well known for its dependability and economy of operation.

The only drawback is that it doesn't have an engine.

So this year, as an optional extra, you can order the 1212 with automatic (below, right). You turn a dial, the engine turns the reels, and the film moves by as fast or slow as you want.

Otherwise, standard equipment remains the same: a $12^{\prime \prime}$ by $12^{\prime \prime}$ screen, high-impact $A B S$ plastic chassis, and a $17 \mathrm{X}$ lens. (22X and $40 \mathrm{X}$ lenses are also available as options.)

But maybe you're interested in something a little fancier.

In that case we'll be happy to show you our model 1414 reader. It's bigger, heavier, and more streamlined than the 1212 . And for the first time it, too, comes in either standard or automatic.

For brochures on this year's models, write: University Microfilms, Dept. I 15, 300 North Zeeb Road, Ann Arbor, Mich. 48106.

\section{University Microfilms XEROX。}
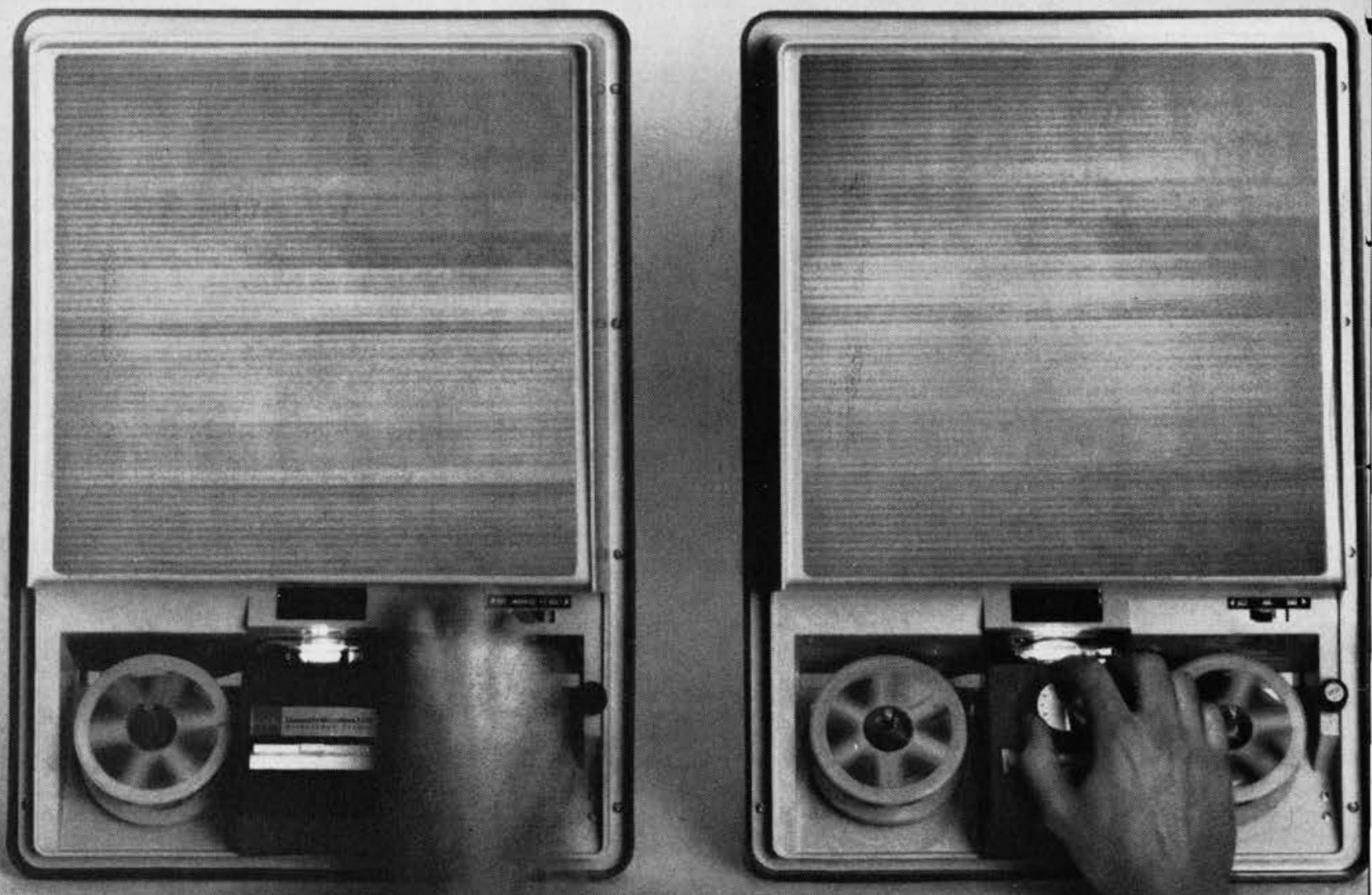